\title{
Influence of jet aeration on pressures around a block embedded in a plunge pool bottom
}

\author{
Rafael Duarte • Anton J. Schleiss • António Pinheiro
}

Received: 5 March 2014 / Accepted: 16 December 2014 / Published online: 1 January 2015

C Springer Science+Business Media Dordrecht 2014

\begin{abstract}
The influence of the air entrained by water jets on the dynamic pressures applied on the bottom of a plunge pool and inside underlying fissures was analyzed with systematic experiments. The large experimental facility reproduced aerated high-velocity jets up to $22.1 \mathrm{~m} / \mathrm{s}$ impinging on a pool and impacting on an instrumented cubic block embedded on the bottom. Plunging and submerged jets are compared, as well as jet impingement on the center or on the side of the block. A relationship is proposed to describe the time-averaged pressures at stagnation as a function of the relative pool depth, considering pressure measurements in this position as well as recent experimental evidence on the jet centerline velocity decay. Air bubbles influence the dynamic pressures on the rock bottom by reducing jet momentum, but also by reducing the jet dissipation rates in the water pool. These two processes are opposed. The reduction of momentum, consequence of a jet with a lower apparent density, results in lower pressures, while lower jet dissipation in the pool results in higher kinetic energy of the jet impacting the bottom and higher pressures. Finally, the spectral contents show that the resonance frequencies of aerated jets are shifted as a consequence of wave celerity reduction caused by lower mean densities inside the fissures, which is an evidence of the presence of air bubbles.
\end{abstract}

Keywords Air entrainment - Plunging jets - Submerged jets · Rock scour - Plunge pool · High-velocity jets

R. Duarte $(\varangle) \cdot$ A. J. Schleiss

Laboratory of Hydraulic Constructions (LCH), Ecole Polytechnique Fédérale de Lausanne (EPFL),

Station 18, 1015 Lausanne, Switzerland

e-mail: rafael.duarte@alumni.epfl.ch

A. J. Schleiss

e-mail: anton.schleiss@epfl.ch

A. Pinheiro

CEHIDRO, Instituto Superior Técnico, Universidade de Lisboa, Av. Rovisco Pais,

1049-001 Lisbon, Portugal

e-mail: antonio.pinheiro@tecnico.ulisboa.pt 


\section{Introduction}

\subsection{Background}

Ultimately, dynamic pressures applied on the bottom of a plunge pool and inside rock fissures are responsible for block uplift and, as a consequence, for the formation of a scour hole downstream of high-velocity water jets. If the case of jets issued from flood release structures of high-head dams is considered, the whole process is composed by a water jet that plunges into the pool, entraining large air quantities. Subsequently, a diffusion process takes place by shear of the jet penetrating the pool. The energy of the jet that is not dissipated in the pool is then acting on the rock bottom and also transmitted to the rock joints in the form of dynamic pressures [6]. Rock joint fracturing and block uplift are a direct consequence of these pressure fluctuations.

Ervine et al. [18] performed a theoretical and experimental research and provided the basis for the analysis of pressure fluctuations in plunge pool floors impacted by plunging jets. The rather similar case of pressure fluctuations caused by hydraulic jumps on the bottom of stilling basins was studied by Fiorotto and Rinaldo [20], while Bellin and Fiorotto [1] assessed uplift forces on concrete slabs subjected to hydraulic jumps. Melo et al. [26] investigated pressure fluctuations on concrete slabs due to impacting jets and Pinheiro and Melo [28] propose a buoyancy coefficient to account for the effect of jet aeration on the pressures applied on concrete slabs.

Bollaert [6] and Bollaert and Schleiss [8] conducted the first study to systematically assess pressure fluctuations in joints due to high-velocity jets. The large experimental facility produced near-prototype jet velocities up to approximately $30 \mathrm{~m} / \mathrm{s}$, and pressures were assessed in 4 closed-end joints and 1 open-end joint. Bollaert [6] stated that rock joints are subject to either a brittle failure, generated by short-duration pressure peaks or to failure by fatigue generated by cyclic loadings. Hence, he showed that the consideration of the transient characteristics of the pressure waves inside rock joints is essential for rock scour assessment, as resonance phenomena might amplify peak pressures and influence joint failure. A similar behavior was found by Müller et al. [27] for the case of coastal blockwork structures impacted by breaking waves. They found experimentally that pressure waves can propagate within the fissures of the structure and present resonance properties which might contribute to their collapse.

Later, Federspiel [19] modified the representation of the pool bottom by implementing an instrumented metallic cubic block, thus creating an open three dimensional (3D) fissure. He assessed block displacements and the corresponding pressure fields around the block impacted by plunging high-velocity water jets impinging on different positions of the block.

Bollaert and Schleiss [7] performed a state-of-the-art review of existing methods for rock scour assessment, and classified the past developments into the three main axes: water, rock and air. Currently, even if gaps still exist, the hydraulic features are rather well understood, considering jet development in the air and the hydraulic shear layer in the pool, pressure fluctuations on the water-rock interface and transient pressures inside underlying fissures. Fewer studies, such as the ones cited above, investigated fluid-structure interactions between water and rock, which take into consideration rock properties.

To the Authors knowledge, no study has ever assessed systematically the influence of air entrainment on the dynamic pressures on the water-rock interface and underlying fissures impacted by high-velocity jets. This study aims at filling this gap by assessing the influence of the incoming jet aeration on the dynamic pressures around a block embedded on the bottom of a plunge pool. 


\subsection{Theoretical aspects}

Detailed descriptions of air entrainment features and of the development of aerated jets in plunge pools are provided by Bin [4], Ervine [16] and Chanson [10]. On the water-rock interface, the remaining kinetic energy of the turbulent jet is converted into dynamic pressures. Difference is made if the pool depth $Y$ is smaller or larger than the core development length $y_{c}$ required for the jet core to vanish. If $Y<y_{c}$, a core jet impact is observed on the pool bottom. The jet hits the water-rock interface with almost the same kinetic energy it entered the pool at the plunge section. The core of the jet generates on the bottom high mean pressures with relatively low fluctuations. On the other hand, if $Y>y_{c}$, a developed jet impact occurs at the bottom. In this case, the time-averaged pressures decrease with increasing pool depth.

On the bottom, the radial function of the time-averaged pressures follows a simple Gaussian distribution $[3,18]$, similarly to the velocity distribution of a transversal section of the vertical jet in the pool. The intersection of the jet centerline with the pool bottom is called stagnation. At this point, the pressures are at a maximum value and velocity is zero. The region in the vicinity of the stagnation point is the impingement region, where the jet is slowed by the bottom, resulting in a pressure build-up [2,3,15]. The jet is deflected outwards the impingement region, creating a wall jet, with velocity parallel to the bottom and increasing with radial distance from the jet axis (Fig. 1). The energy fluctuations at the entrance of the rock joints in the water-rock interface provide the excitation signal for the pressures waves that propagate inside the fissures, which can be analyzed as closed-conduits subject to transient phenomena [9]. Two distinct cases are of interest to this study: a vertical jet impinging on the center of a block, namely a centered jet, or directly on a fissure, namely a sided jet.

When the jet impinges on the center of the block and if transient phenomena inside the fissures are neglected, symmetry dictates that the flow inside the fissures is zero, and that the time-averaged pressures due to the jet are constant. These pressures are low compared to the upper side of the block. Hence, the net force applied on the block pulls it further down and no dynamic uplift occurs.

In the case of a jet impinging on the side of the block, a relatively high fraction of the energy is transmitted into the fissures. A flow occurs due to energy differences in the fissure extremes, and time-averaged pressures decay linearly with the distance from the fissure entrance. A net dynamic uplift pressure may be acting in this case.

Nevertheless, if transient phenomena inside rock fissures are considered, pressure wave superposition and amplification occur, with resonance properties strongly influenced by the air content inside the joints. Significant oscillatory and resonance pressures have been observed by Bollaert and Schleiss [8] in closed-end 1D joints.

\section{Experiments}

\subsection{Experimental arrangement}

The large facility (Fig. 2) was built at the Laboratory of Hydraulic Constructions of the Ecole Polytechnique Fédérale de Lausanne $[8,13,14]$. Table 1 gives the studied test configurations.

The vertical jets were issued from a $72 \mathrm{~mm}$ diameter outlet nozzle. The velocity distribution at the issuance section is uniform, due to the use of a honeycomb grid and air vent $[24,25]$. Turbulence intensities $T_{u}$ close to the issuance section were assessed experimentally by Manso et al. [25] in the longitudinal direction and are approximately $8 \%$ for the 
a) Centered jet

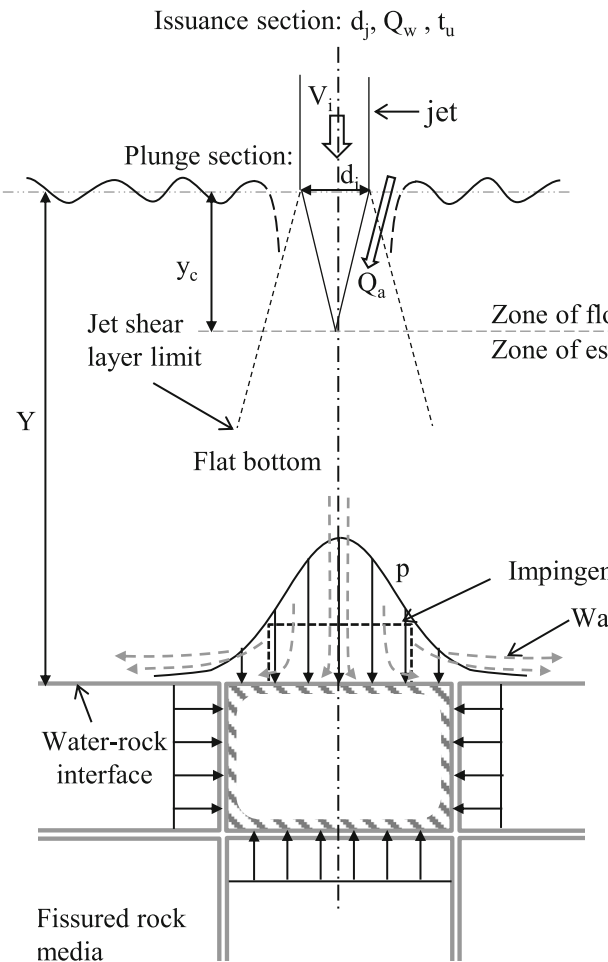

b) Sided jet

$$
\text { Issuance section: } d_{j}, Q_{w}, t_{u}
$$

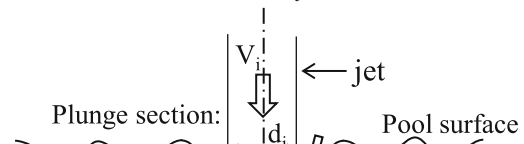

Fig. 1 Sketch of time-averaged pressure field around a block embedded in a flat rock bottom and main parameters for centered jets (a) and sided jets (b)

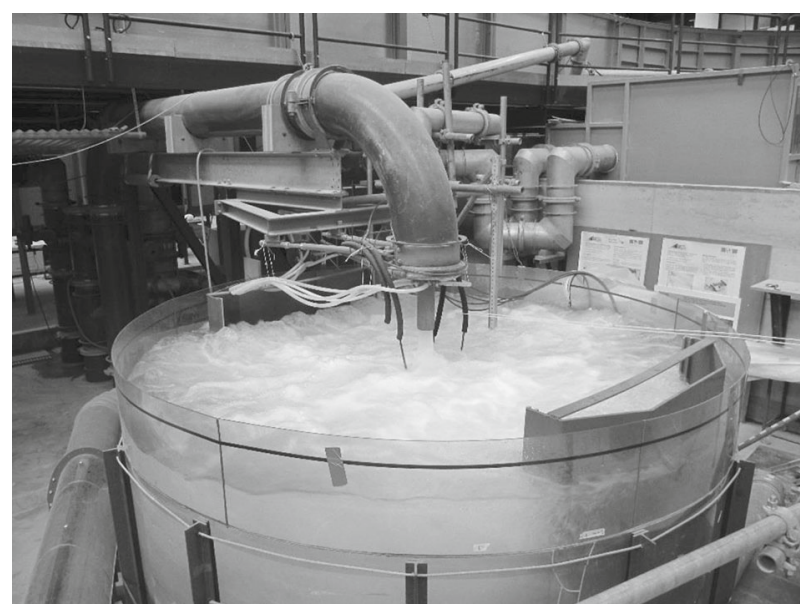

Fig. 2 Photograph of the experimental facility during the tests 
Table 1 Tested configurations

\begin{tabular}{|c|c|c|c|c|}
\hline \multirow{3}{*}{ Impingement positions } & \multirow{3}{*}{ Impingement types } & Pool depth & Total jet discharge & $\begin{array}{c}\text { Jet aeration at } \\
\text { issuance }\end{array}$ \\
\hline & & Y & $Q_{a w}$ & $\beta_{1}$ \\
\hline & & $(\mathrm{cm})$ & $(1 / \mathrm{s})$ & $(\%)$ \\
\hline \multirow[b]{2}{*}{ Centered jets } & Plunging jets & $30,50,80$ & \multirow{3}{*}{$\begin{array}{c}30,40,50,60 \\
\quad 70,80,90\end{array}$} & \multirow{3}{*}{$0,8,15,23$} \\
\hline & Submerged jets & 70 & & \\
\hline Sided jets & Plunging jets & $30,50,80$ & & \\
\hline
\end{tabular}

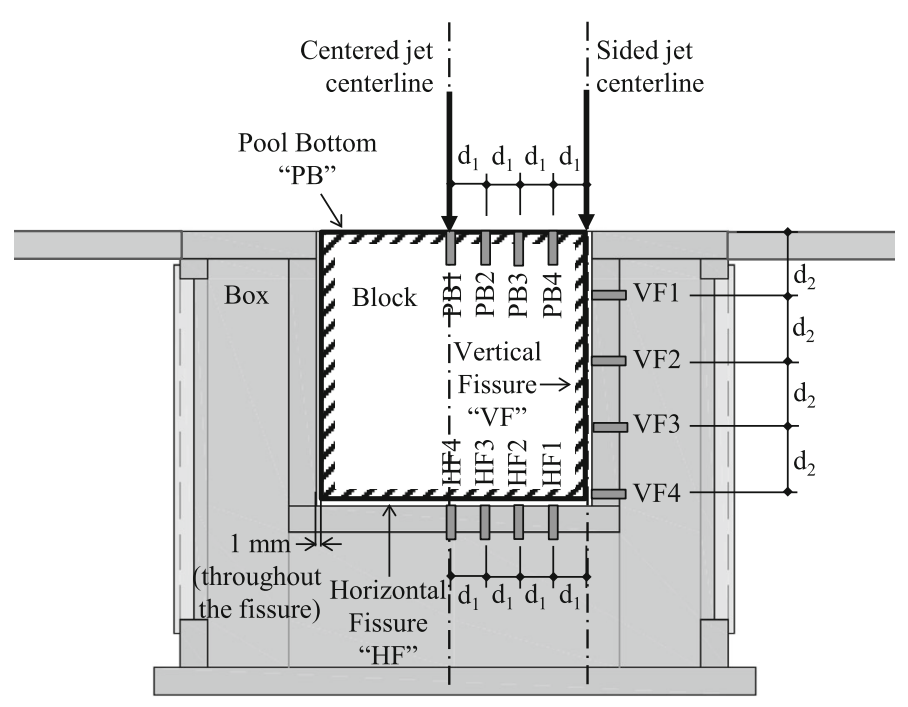

Fig. 3 Schematic detail of the instrumented box and block and jet impingement positions; $d_{1}=25 \mathrm{~mm}$ and $d_{2}=50 \mathrm{~mm} ; P B 1-4$ pressure transducers positions on the pool bottom, $V F 1-4$ pressure transducers positions on the vertical fissure, $H F 1-4$ pressure transducers positions on the horizontal fissure

lower jet velocities, reducing asymptotically towards values between 4 and $5 \%$ for high jet velocities.

Aeration of the issued water jets was obtained by adding compressed air into the nozzle. The jets impinged into a $3 \mathrm{~m}$ diameter cylindrical basin composed of steel reinforced plastic walls, either on the center or on the fissure entrance on the side of the block.

Plunging jets were tested for pool depths $Y$ of 30,50 or $80 \mathrm{~cm}$, resulting in relative pool depths $Y / d_{j}$ of $4.2,6.9$ and 11.1. The plunging jet nozzle outlet was $1 \mathrm{~m}$ above the pool bottom. Additionally, submerged jets were tested with an extended nozzle whose outlet was $70 \mathrm{~cm}$ above the pool bottom $\left(Y / d_{j}=9.7\right)$.

On the bottom of the pool, Federspiel [19] implemented a metallic system to represent fully open $3 \mathrm{D}$ fissures on the rock mass. It comprises a box with a cavity $201 \mathrm{~mm}$ deep and $202 \times 202 \mathrm{~mm}$ wide, where a $200 \mathrm{~mm}$ side cubic block is inserted (Fig. 3). Therefore, a $1 \mathrm{~mm}$ thick fissure exists between the block and the box. Lateral guides were used on the block to maintain this thickness and to ensure a 1 degree of freedom vertical displacement, minimizing 
block rotations. Furthermore, the block was fixed inside the cavity by steel plates specially conceived to this purpose.

Dynamic pressures were measured at 12 positions uniformly distributed along one half of the block (Fig. 3), being 4 on the pool bottom ("PB1"-"PB4"), 4 on the vertical fissure ("VF1"-"VF4") and 4 on the horizontal fissure ("HF1"-"HF4"). The pressure transducers were of type Kulite HKM-375M-17-BAR-A. These sensors measure absolute pressures in the range between 0 and 17 bars with a precision of $\pm 0.1 \%$ of the full-scale output and have a resonance frequency of $750 \mathrm{kHz}$. The acquisition card is a National Instruments type USB-6259 series M, driven with laboratory developed routine. No filtering was applied to the obtained signals.

The pressure transducers were calibrated by Federspiel [19] using a reference transducer and calibration checks were performed three times on the model during this study. In all cases, the supplier's calibration curves were confirmed.

Each test scenario was performed at least three times to check the repeatability of the results. Plunging and submerged centered jets with fixed block and respectively 80 or $70 \mathrm{~cm}$ deep pool were repeated 6 times per scenario in different dates. In each test run 65,536 samples were measured with an acquisition frequency of $1 \mathrm{kHz}$. Bollaert [6] and Manso [24] performed sensitivity analysis and concluded that this frequency is sufficient to evaluate the relevant pressure fluctuations and the spectral contents of the pressure signals.

\subsection{Data analysis procedure}

\subsubsection{Issuance parameters}

The total issued jet discharge $Q_{a w}$ at the nozzle outlet is the sum of the incoming water discharge $Q_{w}$ and the air discharge $Q_{a}$ pumped into the nozzle. The issued jet discharges used in this study are shown in Table 1 and result in total issued jet velocities $V_{a w}$ ranging from 7.4 to $22.1 \mathrm{~m} / \mathrm{s}$. Hence, the jets are issued with an upstream jet aeration $\beta_{1}=Q_{a a} / Q_{w}$ and the related air concentration at issuance is $C_{a a}=\beta_{1} /\left(1+\beta_{1}\right)$.

For the plunging jet case, a relevant additional amount of air is entrained at the plunge section (see Fig. 1). However, in the case of submerged jets, $Q_{a a}$ can be considered equal in good approximation to the total air discharge $Q_{a}$ entrained into the pool, since the influence of recirculating bubbles and air entrainment in the undulating pool surface can be neglected. Both effects increase with the jet discharge but remain small compared to $Q_{a a}$. Hence, $\beta_{1}=\beta$ for submerged jets, where $\beta=Q_{a} / Q_{w}$ is the total jet aeration (or alternatively air-to-water ratio). The related total entrained air concentration is $C_{a}=Q_{a} / Q_{a w}=\beta /(1+\beta)$.

For each total jet discharge, four values of issuance aeration $\beta_{1}$ were tested (Table 1 ). It may be assumed that the jets are uniformly aerated when leaving the nozzle. Thus, jets of similar issuance velocity but different mean density $\rho_{a w}$ are obtained. If $\rho_{w}$ is the water density and $\rho_{a}$ is the air density, the mean jet density at the nozzle issuance section is given by:

$$
\rho_{a w}=\frac{1}{1+\beta_{1}} \rho_{w}+\frac{\beta_{1}}{1+\beta_{1}} \rho_{a} .
$$

\subsubsection{Plunge section parameters}

After passing through the air, plunging jets impact the pool surface with total velocity $V_{i}$ and diameter $d_{i}$ influenced by gravity acceleration. In the case of submerged jets, issuance and impact sections are the same, thus $V_{i}=V_{a w}$ and $d_{i}=d_{j}=72 \mathrm{~mm}$. 
The kinetic energy per unit volume of the jets impacting in the pool surface can thus be derived:

$$
E_{k}=\frac{1}{2} \rho_{a w} V_{i}^{2}
$$

\subsubsection{Block parameters}

The dynamic pressures around the block are analyzed by means of non-dimensional pressure coefficients and the spectral contents of the pressure fluctuations. The dynamic pressure coefficients are obtained using the following expressions:

$$
\begin{aligned}
& C_{p}=\frac{p_{\text {mean }}-\rho_{w} g Y^{\prime}}{\frac{1}{2} \rho_{a w} V_{i}^{2}}, \\
& C_{p}^{\prime}=\frac{p^{\prime}}{\frac{1}{2} \rho_{a w} V_{i}^{2}}, \\
& C_{p}^{+}=\frac{p_{\text {max }}-\rho_{w} g Y^{\prime}}{\frac{1}{2} \rho_{a w} V_{i}^{2}}, \\
& C_{p}^{-}=\frac{p_{\text {min }}-\rho_{w} g Y^{\prime}}{\frac{1}{2} \rho_{a w} V_{i}^{2}},
\end{aligned}
$$

where $g$ is the gravity acceleration, $Y^{\prime}$ is the distance between the pressure transducer and the pool surface and $p_{\text {mean }}, p^{\prime}, p_{\max }$ and $p_{\min }$ are, respectively, the average pressure, the RMS value of the pressure fluctuations, and the extreme maximum and minimum observed pressures. Only relative pressures regarding atmospheric pressure are considered.

$C_{p}$ represents non-dimensional time-averaged pressure values. It can also be interpreted as the fraction of the incoming jet kinetic energy that has not been previously dissipated in the pool. Similarly, $C_{p}^{\prime}, C_{p}^{+}$and $C_{p}^{-}$represent the pressure fluctuations and extreme pressure values compared to the energy of the jet.

Power spectral densities (PSDs) of the pressure fluctuations were obtained using a Welch periodogram-based fast Fourier transform. The pressure fluctuation signals, composed of $2^{16}$ samples, are divided into 64 segments sampled by a Hamming window with $50 \%$ overlapping.

\subsection{Scale effects}

Pressure fluctuations on a plunge pool bottom and inside underlying fissures due to turbulent aerated high-velocity jets are a result of a series of complex phenomena. These phenomena are related to the aerated jet development through the air and the pool [10-12], conversion of kinetic energy into turbulent dynamic pressures and transient phenomena of the aerated pressure waves inside fissures.

Heller [22] and Chanson [11] propose that the Reynolds $R_{e}$ and Weber $W_{e}$ numbers of the jets should be larger than $1 \times 10^{5}$ and $1 \times 10^{3}$, respectively, to minimize the scale effects on a Froude $F_{r}$ similarity model. These limits are respected in this study, since the minimum values of $R_{e}$ and $W_{e}$ were $4.7 \times 10^{5}$ and $5.3 \times 10^{4}$, respectively.

With the objective of minimizing scale effects related to the dynamic pressures around a rock block, near-prototype jet velocities up to $22.1 \mathrm{~m} / \mathrm{s}$ are reproduced. Prototype conditions studied by Ervine et al. [18], Bollaert [6] and Manso et al. [25] lead to jet velocities and turbulence intensities close to the ones used in this study.

Thus, the non-dimensional pressure coefficients, as well as the spectral ranges of the pressure signals are considered to correspond well to prototype conditions. However, it is 
acknowledged that the experimental facility is a geometrically reduced scale representation of prototype structures. For instance, scale effects might arise from the proportions between jet diameter and block side length.

Additionally, the 3D open-fissure model is a simplified representation of a highly complex 3D net of rock fissure patterns, where pressure wave partial reflections can occur nearly anywhere. Nevertheless, the simplified model allows a better understanding of the complex phenomena involved in the influence of air entrainment on dynamic pressures around a block, and adds knowledge to recent developments on rock scour assessment.

\section{Results and discussion}

\subsection{Time domain analysis}

\subsubsection{General behavior of pressures around the block}

An overview of the time-averaged pressure coefficients around the block for non-aerated jets is shown in Fig. 4 for a total jet velocity $V_{a w}=22.1 \mathrm{~m} / \mathrm{s}$ plunging into a relatively deep pool $\left(Y / d_{j}=11.1\right)$. A comparison is made between a centered jet and a sided jet.

The behavior is similar on the water-rock interface, where a radian Gaussian decay is observed. For the mean pressures, Ervine et al. [18] proposed:

$$
\frac{C_{p}}{C_{p c l}}=\exp \left[-K_{2}\left(\frac{r}{Y}\right)^{2}\right]
$$

where $C_{p c l}$ is the mean pressure coefficient in the jet centerline and $K_{2}$ is a parameter that determines the decay rate. According to Ervine et al. [18], $K_{2}$ ranged from 30 for shallow pools, to 50 for deeper pools. In this study, $K_{2}$ was found to vary roughly between 25 for $Y / d_{j}=4.2$ and 250 for $Y / d_{j}=11.1$. Additionally, in a general way, all the time-averaged pressure coefficients were found to decay exponentially as a function of the radial distance from the jet centerline in the pool bottom.

Inside fissures, the behavior for centered and sided jets change. For centered jets, the pressures inside the fissures are small because of the distance from the jet centerline. Then, mean pressures, pressure fluctuations and extreme pressures slightly increase towards the center of the fissure, as it can be seen more clearly in the unfolded view in Fig. 5. A symmetric behavior is assumed for centered jets. Sided jets produce higher pressures in the entrance of the fissures, which decay almost linearly with the fissure length.

\subsubsection{Pressures at stagnation}

With the aim of describing the decay of the time-averaged pressure coefficient at stagnation due to plunging water jets as a function of the relative pool depth, Ervine et al. [18] proposed:

$$
C_{p}=38.4\left(1-C_{a}\right)\left(\frac{d_{i}}{Y}\right)^{2},
$$

where the entrained air concentration $C_{a}$ was derived from the air to water ratio $\beta$ using the following empirical expression [18]:

$$
\beta=K_{1}\left(1-\frac{V_{e}}{V_{i}}\right) \sqrt{\frac{L}{d_{i}}} .
$$


(a) Centered jet

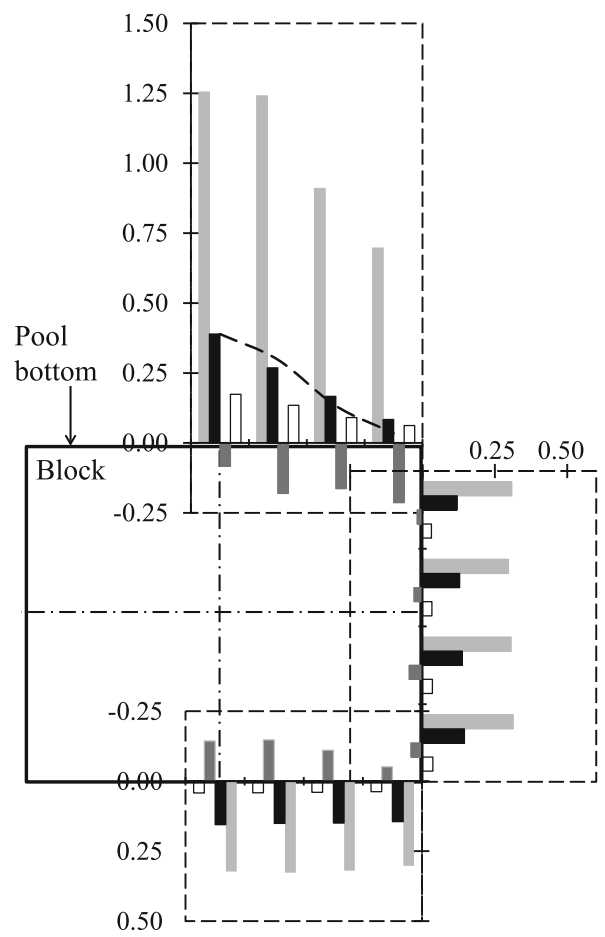

(b)

Sided jet

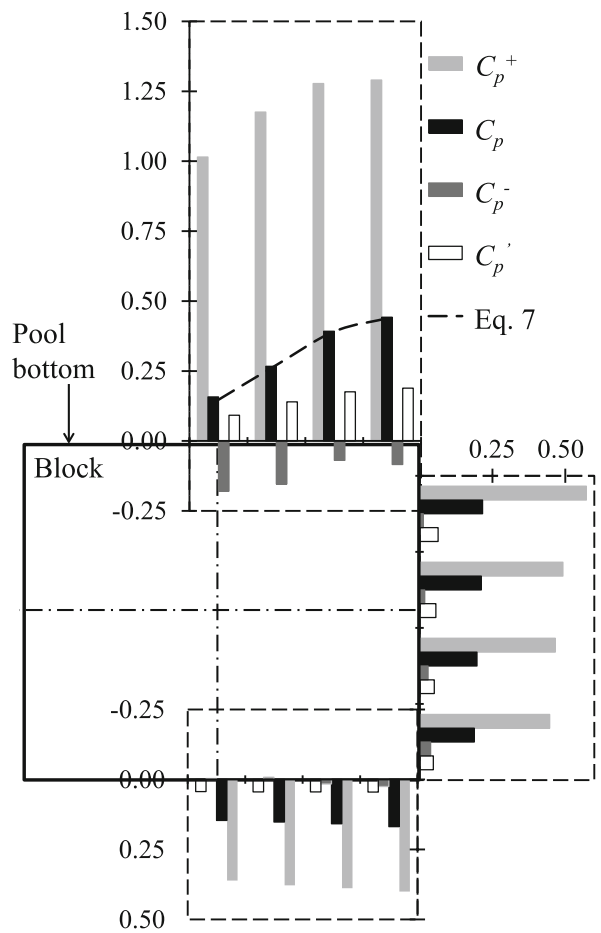

Fig. 4 Pressure coefficients around block. Non-aerated jet $\left(\beta_{1}=0 \%\right), V_{a w}=22.1 \mathrm{~m} / \mathrm{s}$, block free, $Y / d_{j}=$ 11.1; (light grey bars) $C_{p}^{+}$; (black bars) $C_{p}$; (dark grey bars) $C_{p}^{-}$; (white bars) $C_{p}^{\prime}$; (dashed line) Eq. 7 ; $\mathbf{a}$ centered jet and $\mathbf{b}$ sided jet

In Eq. 9, $V_{e}$ is the onset jet impact velocity at the plunge section above which the air entrainment process takes place, considered about $1 \mathrm{~m} / \mathrm{s}, L$ is the jet fall length between the issuance and plunge sections and $K_{1}$ is a parameter that varies between 0.2 for smooth jets to 0.4 for very rough turbulent jets.

Direct measurements of the jet velocities in the pool performed by the Authors allowed describing the time-averaged jet centerline velocity $V$ as a constant value in zone of flow development, where the core of the jet still persists, followed by a linear decay in the zone of established flow. The following expression could be derived:

$$
\frac{V}{V_{i}}=A-0.07 \frac{y-y_{c}}{d_{i}} \text { if } y>y_{c},
$$

where $A$ is a threshold constant value for the jet centerline velocity in the jet core. For submerged jets, $A=1$, meaning that the jet impact velocity remains the same while the core persists, and for plunging jets, $A=0.83$ as a result of energy loss at the plunge section. The length of core decay $y_{c}$ could also be obtained empirically:

$$
\begin{cases}y_{c} / d_{i}=7.74 \times 10^{-6}\left(V_{i} d_{i}\right) / v & \text { if } y_{c} / d_{i} \leq A^{\prime}, \\ y_{c} / d_{i}=A^{\prime} & \text { if } y_{c} / d_{i}>A^{\prime},\end{cases}
$$



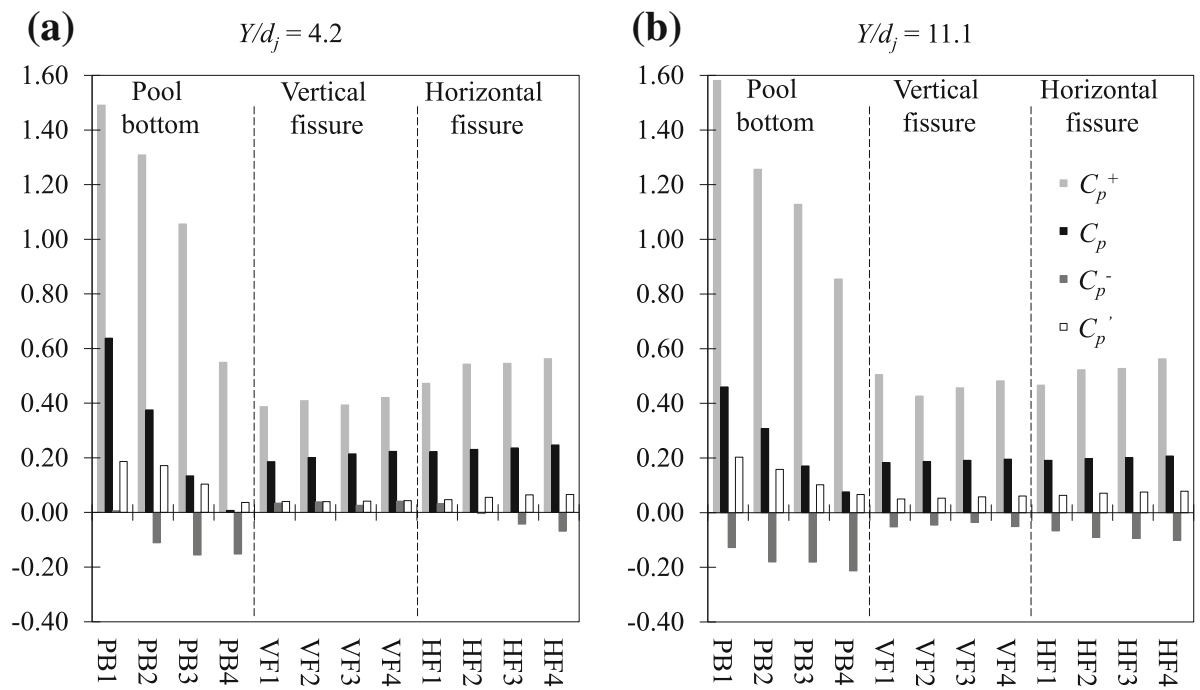

Fig. 5 Detailed view of pressure coefficients around the block. Centered non-aerated jet $\left(\beta_{1}=0 \%\right), V_{a w}=$ $22.1 \mathrm{~m} / \mathrm{s}$, block free, $Y / d_{j}=11.1$; (light grey bars) $C_{p}^{+} ;$(black bars) $C_{p} ;$ (dark grey bars) $C_{p}^{-} ;($white bars) $C_{p}^{\prime} ; \mathbf{a} Y / d_{j}=4.2$ and $\mathbf{b} Y / d_{j}=11.1$

where $v$ is the kinematic viscosity of the fluid. The parameter $A^{\prime}$ is 3.5 for submerged jets and 7.8 for plunging jets. The term $V_{i} d_{i} / v$ corresponds to the Reynolds number of the jet at the plunge section.

The kinetic energy per unit volume of the jet is converted into dynamic pressures at the water-rock interface. For this reason, the time-averaged pressure coefficient may be derived from the mean jet velocities. Taking into consideration Eqs. 8-10 for the kinetic energy, $C_{p}$ and the centerline velocity, an expression of the following form could be obtained theoretically for the time-averaged pressure coefficient:

$$
C_{p}=\psi\left(A-0.07 \frac{Y-y_{c}}{d_{i}}\right)^{2} \text { if } y>y_{c},
$$

were the term $\psi$ reflects the loss of kinetic energy that takes place in the impingement region.

The analysis of the experimental results showed that $\psi$ strongly depends on the incoming jet velocity, differently from the jet development in the free jet region above. The best fit of the experimental data for non-aerated plunging jets yields:

$$
\begin{aligned}
C_{p} & =\psi\left(0.926-0.0779 \frac{Y-y_{c}}{d_{i}}\right)^{2} \text { if } y>y_{c}, \\
\psi & =\frac{1}{1+\exp \left[-5.37 \times 10^{-6}\left(V_{i} d_{i} / v-6.63 \times 10^{5}\right)\right]} .
\end{aligned}
$$

Figure 6 shows the experimental results of $C_{p}$ at stagnation as a function of the relative pool depth, compared to Eq. 13 for the different incoming jet velocities of non-aerated plunging and submerged jets.

Time-averaged pressure coefficient can be fairly well derived from jet centerline velocity decay in the pool. The empirical Eq. 13 is rather similar to the theoretical Eq. 12. It provides physical evidence that low $C_{p}$ values for lower jet velocities are a result of kinetic energy 


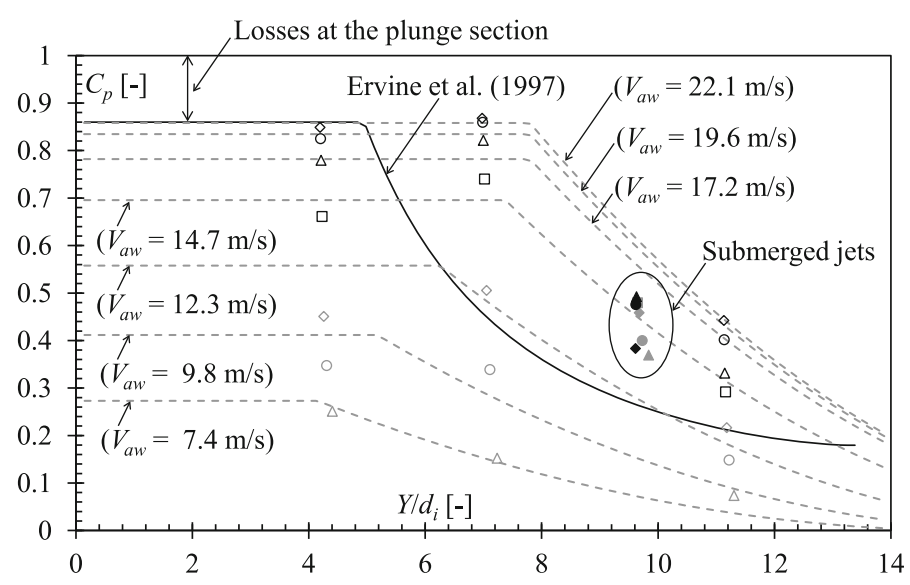

Fig. 6 Mean pressure coefficient $C_{p}$ as a function of the relative pool depth $Y / d_{i}$ for non-aerated jets; (continuous line) Ervine et al. [18]; (dashed line) Eq. 13 for different values of jet velocity $V_{a w}$; experimental data for plunging jets: (open triangles) $V_{a w}=7.4 \mathrm{~m} / \mathrm{s}$, (open circles) $V_{a w}=9.8 \mathrm{~m} / \mathrm{s}$, (open diamonds) $V_{a w}=$ $12.3 \mathrm{~m} / \mathrm{s}$, (open squares) $V_{a w}=14.7 \mathrm{~m} / \mathrm{s}$, (open triangles) $V_{a w}=17.2 \mathrm{~m} / \mathrm{s}$, (open circles) $V_{a w}=19.6 \mathrm{~m} / \mathrm{s}$, (open diamonds) $V_{a w}=22.1 \mathrm{~m} / \mathrm{s}$, experimental data for submerged jets. (filled grey triangles) $V_{a w}=7.4 \mathrm{~m} / \mathrm{s}$, (filled grey circles) $V_{a w}=9.8 \mathrm{~m} / \mathrm{s}$, (filled grey diamonds) $V_{a w}=12.3 \mathrm{~m} / \mathrm{s}$, (filled squares) $V_{a w}=14.7 \mathrm{~m} / \mathrm{s}$, (filled triangles) $V_{a w}=17.2 \mathrm{~m} / \mathrm{s}$, (filled circles) $V_{a w}=19.6 \mathrm{~m} / \mathrm{s}$, (filled diamonds) $V_{a w}=22.1 \mathrm{~m} / \mathrm{s}$

dissipation in the impingement region rather than in the zone of established flow, where jets of different velocities dissipate similarly. The term $\psi$ is a logistic function of the impact velocity, asymptotically reaching the value 1 for high-velocity jets.

Figure 6 shows that $C_{p}$ values for a core jet at stagnation $\left(Y<y_{c}\right)$ have an upper limit that corresponds to the one proposed by Ervine et al. [18] of approximately 0.86. This limit is asymptotically reached for the high-velocity jets. Higher $C_{p}$ values cannot be observed due to energy loss at the plunge section.

The $C_{p}$ results for submerged jets, which were tested for 1 pool depth only, are grouped together in a narrow zone, showing that they are much less dependent on the jet velocity.

\subsubsection{Influence of jet aeration}

Mean pressures Ervine and Falvey [17] stated that the entrainment of air bubbles in the diffusing shear layer in the plunge pool reduces the mean dynamic pressures on the bottom. Their reasoning is based on the reduction of momentum, consequence of a void fraction of the incoming jet, and yields:

$$
\frac{p_{\text {mean (aerated jet })}}{\frac{1}{2} \rho_{w} V_{i}^{2}}=\frac{\frac{1}{2} \rho_{w}\left(1-C_{a}\right) V_{i}^{2}}{\frac{1}{2} \rho_{w} V_{i}^{2}}=\left(1-C_{a}\right) .
$$

Equation 15 compares the mean pressures of an aerated jet with the kinetic energy of a clear-water jet of the same velocity. Although its simplicity, Eq. 15 is useful because it shows that, if the dissipation in the pool is neglected-or similar to that of a clear-water jet, an aerated jet produces mean pressures that are lower than those of a water jet, proportionally to its water fraction $\left(1-C_{a}\right)$. The same reasoning would lead to similar $C_{p}$ results for different jet aerations considering Eq. 3, if the dissipation conditions in the pool are the same. Indeed, the non-dimensional dynamic pressure coefficients are computed relatively to the kinetic 
(a)

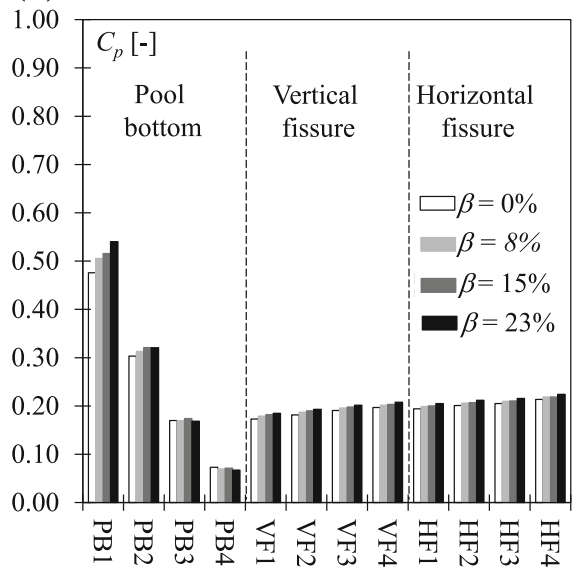

(c)

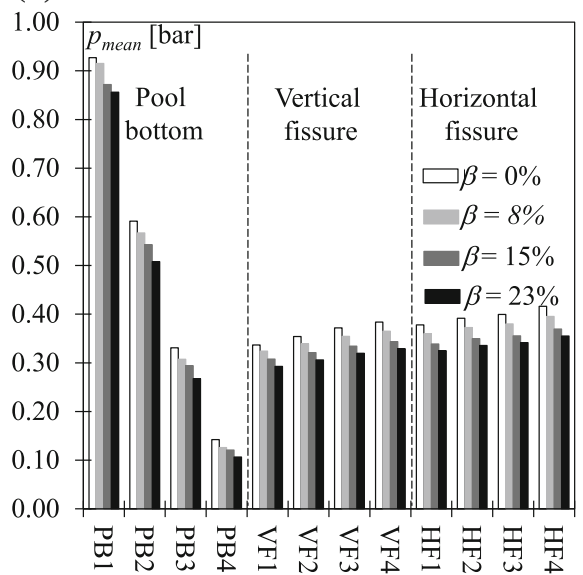

(b)

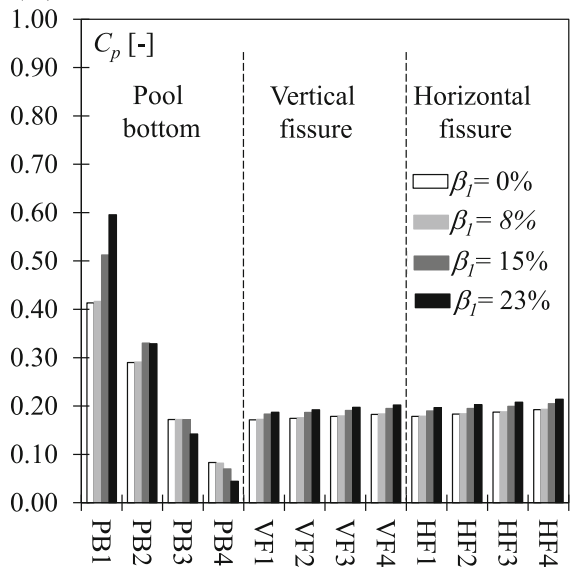

(d)

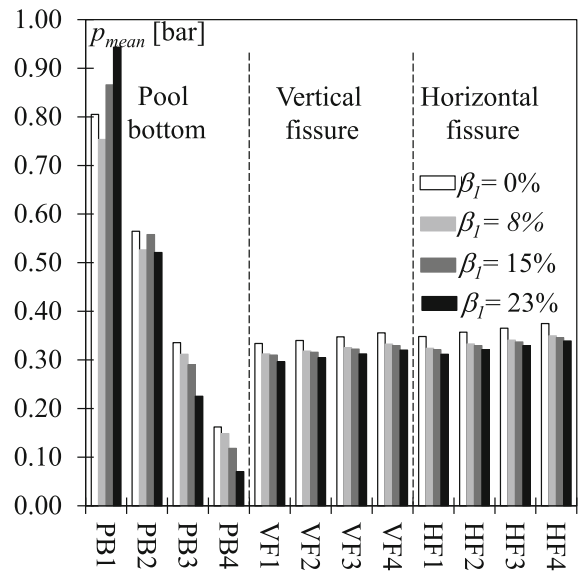

Fig. 7 Influence of the incoming jet aeration $\beta_{1}$ on the time-averaged pressures $p_{\text {mean }}$ and pressure coefficients $C_{p}$ around the block; centered jets, fixed block, $V_{a w}=19.6 \mathrm{~m} / \mathrm{s} ; \mathbf{a}$, c submerged jet; $Y / d_{j}=9.7$ and b, d plunging jet; $Y / d_{j}=11.1$

energy per unit volume of the jet, which already accounts for the apparent density of the air-water mixture and, consequently, for the lower momentum of aerated jets.

In this study, the total jet aeration is known for the submerged jets. Figure 7 shows timeaveraged pressures and coefficients around the block generated by submerged and plunging jets.

The time-averaged pressure coefficients for submerged jets (Fig. 7a) are rather similar for different jet aerations, especially inside the fissures. A slight increase indicates that jet diffusion in the pool is different for jets with different air content. Nevertheless, the reduction in the jet momentum remains the main process of pressure reduction on the pool bottom.

However, for plunging jets (Fig. 7b, d) on the pool bottom at stagnation (PB1), an inversion occurs and even the absolute pressures increase with jet aeration. This is a consequence of the reduction of kinetic energy dissipation due to shear stress and consequent increase of velocity in the zone of established flow caused by the large air quantities entrained by plunging jets. 
(a) Submerged jet, at stagnation (PB1)

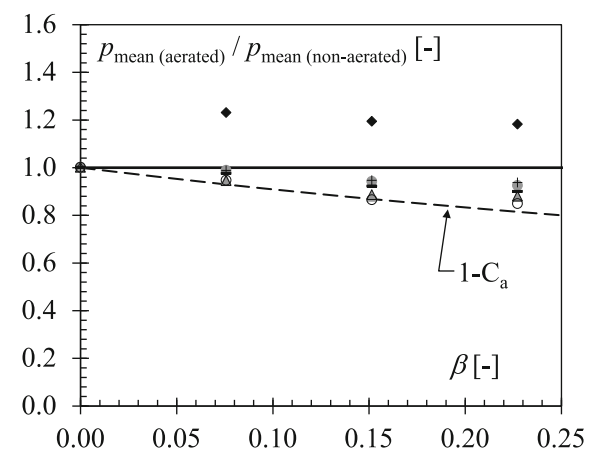

(c) Plunging jet, at stagnation (PB1)

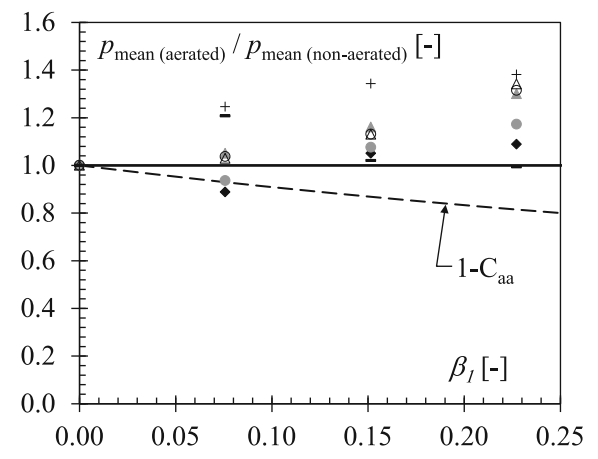

(b) Submerged jet, fissure entrance (VF1)

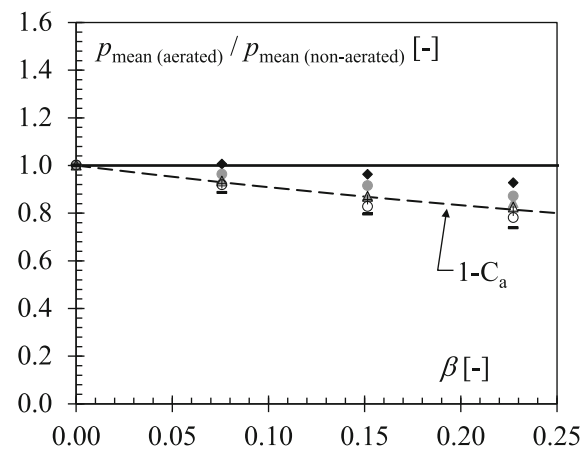

(d) Plunging jet, fissure entrance (VF1)

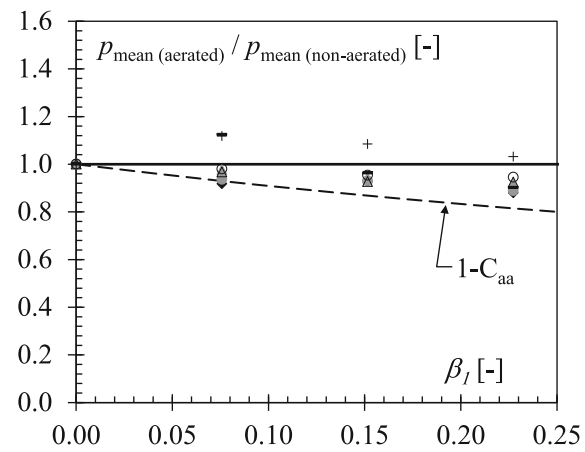

Fig. 8 Relative aerated pressures as a function of the incoming jet aeration, centered jets, fixed block; a, b submerged jets, $Y / d_{j}=9.7 ; \mathbf{c}, \mathbf{d}$ plunging jets, $Y / d_{j}=11.1 ; \mathbf{a}, \mathbf{c}$ stagnation (PB1) and $\mathbf{b}, \mathbf{d}$ fissure entrance (VF1); (minus) $V_{a w}=7.4 \mathrm{~m} / \mathrm{s}$, (plus) $V_{a w}=9.8 \mathrm{~m} / \mathrm{s}$, (open circles) $V_{a w}=12.3 \mathrm{~m} / \mathrm{s}$, (open triangles) $V_{a w}=$ $14.7 \mathrm{~m} / \mathrm{s}$, (filled triangles) $V_{a w}=17.2 \mathrm{~m} / \mathrm{s}$, (filled circles) $V_{a w}=19.6 \mathrm{~m} / \mathrm{s},\left(\right.$ filled diamonds) $V_{a w}=22.1 \mathrm{~m} / \mathrm{s}$, (dashed line) $1-C_{a a}$

A direct assessment of the influence of jet aeration on the mean pressures may be obtained by dividing the time-averaged pressures of the aerated jets by the time-averaged pressures at the same position of a clear-water jet, which will be called as relative aerated pressure for clarity in the following. It can be precisely computed for submerged jets (Fig. 8a at stagnation-PB1; and Fig. 8b at the fissure entrance, VF1). For the plunging jets, even if the test configurations with $\beta_{1}=0$ still entrain a considerable amount of air at the plunge region, the same procedure of dividing the time-averaged pressures of an aerated jet by the time-averaged pressures of the similar non-aerated jet was used (Fig. 8c at stagnation-PB1; and Fig. 8d at the fissure entrance, VF1).

For the submerged jets, it can be seen in Fig. 8 that the incoming jet aeration mainly causes a reduction of the relative aerated pressures, both at stagnation and inside fissures, with the exception of $V_{a w}=22.1 \mathrm{~m} / \mathrm{s}$ at stagnation. At the fissure entrance (Fig. $8 \mathrm{~b}$ ) the momentum reduction $\left(1-C_{a}\right)$ gives the general trend of the pressure reduction, which is lower as the jet velocities are higher.

For the plunging jets, it is evident that the incoming jet aeration produces higher relative aerated pressures at stagnation as a result of higher velocities in the jet centerline. This may be relevant for the block stability in the case of jets impinging directly over a fissure. 


\section{(a)}

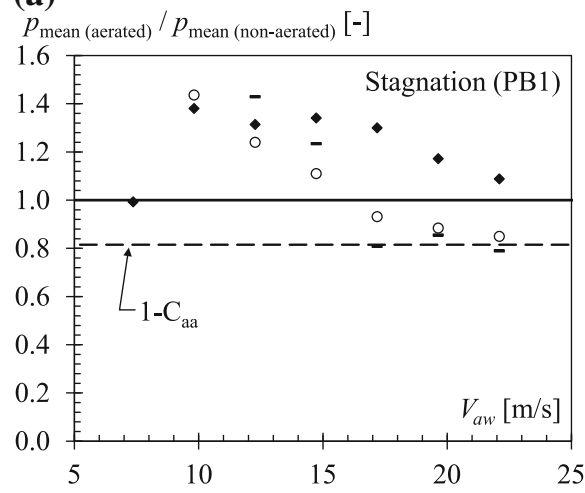

(b)

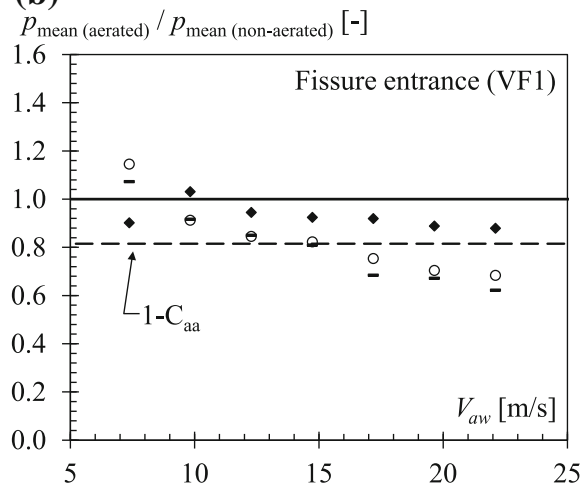

Fig. 9 Relative aerated pressures as a function of the incoming jet velocity $V_{a w}$ for different relative pool depths, centered plunging jets, fixed block; a stagnation $(P B 1)$ and $\mathbf{b}$ fissure entrance $(V F 1),($ minus $) Y / d_{j}=$ 4.2 , (open circles) $Y / d_{j}=6.9$, (filled diamonds) $Y / d_{j}=11.1,($ dashed line $) 1-C_{a a}$

Nevertheless, for the centered jet presented in Fig. 8d, the incoming jet aeration mostly diminishes relative aerated pressures inside the fissures, even if less than the reduction of momentum would lead to. In Fig. 8c, d, note that a curve for $1-C_{a}$ taking into account the whole entrained air concentration would result in a curve lower than $1-C_{a a}$ shown for plunging jets.

The effects of the incoming jet velocity and pool depth on the mean pressures for incoming plunging aerated jets $\left(\beta_{1}=23 \%\right)$ are compared to non-aerated jets in Fig. 9, at stagnation and fissure entrance. It can be confirmed that the aerated centered plunging jets produce more often higher mean pressures at stagnation (Fig. 9a) and lower mean pressures inside fissures (Fig. 9b).

In general, deeper pools generated higher relative aerated pressures compared to shallow pools, both at stagnation and inside fissures. This confirms again that aerated jets reach the bottom with higher velocities by dissipating less energy along the pool trajectory.

Hence, the balance between two physical processes determines the influence of jet aeration. Aerated jets have less momentum due to a lower mean apparent density, which diminishes the pressures around the block. Nevertheless, the entrainment of air bubbles also reduces the shear stresses in the dissipating jet, and jet velocities for aerated jets become higher. This results in a pressure rise, especially close to the jet centerline.

On one hand, pressure rise due to the reduction of jet dissipation is influenced by the entrained air concentration and pool depth. On the other hand, the pressure reduction due to the loss of momentum is influenced by air concentration only, as described in Eq. 15. With increasing jet velocity, the relative importance of jet dissipation reduction in the pool depth decreases and so the relative aerated pressures reduce (Fig. 9a, b).

Pressure fluctuations the RMS values of the pressure fluctuations are shown for submerged and plunging jets in Fig. 10. It can be seen that submerged aerated jets produce higher pressure fluctuations at the pool bottom as well as inside the fissures.

Plunging jets produce higher pressure fluctuations compared to submerged jets, due to an increase in turbulence at the plunge region. The pressure fluctuations around the block for plunging jets have a different in behavior. The jet aeration increases pressure fluctuations at the pool bottom, but reduces pressure fluctuations inside the fissures.

A similar procedure as for the mean pressures is used to analyze the influence of jet aeration in the RMS of the pressure fluctuations. Therefore, the RMS of the pressure fluctuations for 
(a)

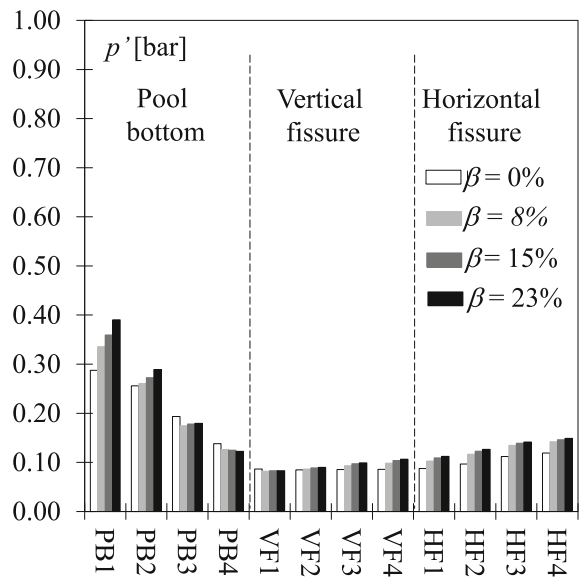

(b)

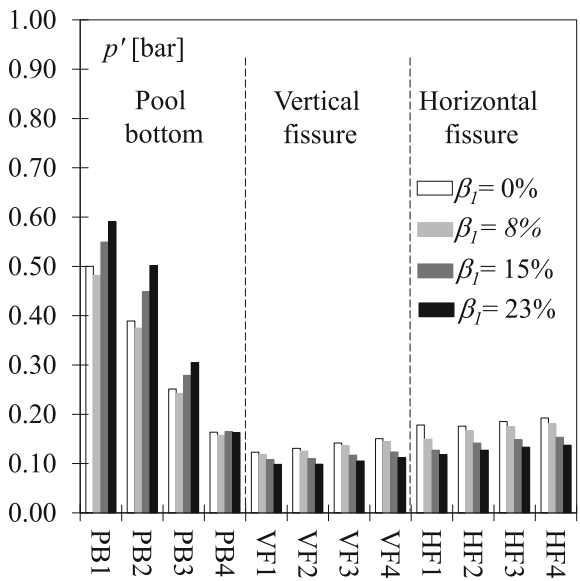

Fig. 10 Influence of the incoming jet aeration on the RMS of pressures fluctuations around the block; centered jets, fixed block, $V_{a w}=22.1 \mathrm{~m} / \mathrm{s} ;$ a submerged jet, $Y / d_{j}=9.7$ and $\mathbf{b}$ plunging jet, $Y / d_{j}=11.1$

an aerated jet is divided by the RMS of the pressure fluctuations for a similar non-aerated jet, which will be called relative aerated RMS for clarity in the following.

Figure 11 shows relative aerated RMS in the same configurations shown in Fig. 8 for relative aerated pressures. At stagnation, relative aerated RMS grows exponentially with jet aeration while, at the fissure entrance, a diminution is observed. Note that, in Fig. 10a for submerged jets, the position VF1 was the only pressure sensor inside the fissure where the RMS of the aerated jets is lower than the one of the non-aerated jet.

The effect of the incoming jet velocity and of the pool depth on the relative aerated RMS is shown in Fig. 12 for plunging centered jets. At stagnation, the deep pool $\left(Y / d_{j}=\right.$ 11.1) produces much higher relative aerated RMS than the shallower pools. The differences between the relative aerated RMS for $Y / d_{j}=11.1$ and for $Y / d_{j}=4.2$ and 6.9 are maximum at jet velocities of approximately $V_{a w}=15 \mathrm{~m} / \mathrm{s}$ and begin to converge toward approximately 1.2 for jets of higher velocities. At the fissure entrance, aerated plunging jets produce lower pressure fluctuations. The relative aerated RMS has a slight tendency to reduce with increasing jet velocity.

\subsection{Frequency domain analysis}

The entrained air bubbles influence not only the dynamic pressure coefficients, but also the structure of the turbulent flow. Especially inside fissures, the air bubbles influence transient phenomena by changing properties of the fluid, such as the apparent fluid density, fluid compressibility and pressure wave celerity. Bollaert [6] stated that air may be present inside rock joints in three manners: dispersed free air bubbles, air bubble cavities and dissolved air.

Figure 13 shows the PSDs $P_{x x}$ of the pressure fluctuations computed for high-velocity plunging centered jets, for selected positions around the fixed block. It can be observed that the positions on the pool bottom have a higher spectral energy, and are clearly distinguishable from the positions inside the fissure. At low frequencies, the spectral contents follow the "unfolded" distance from the jet centerline, and the positions inside the fissures are packed in a narrow band (see Fig. 13a). 
(a) Submerged jet, at stagnation (PB1)

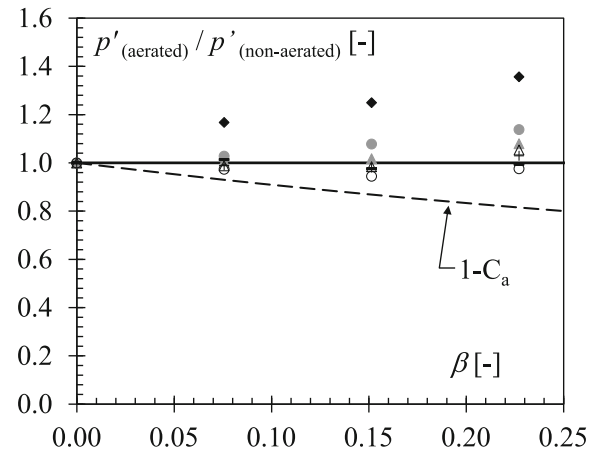

(c) Plunging jet, at stagnation (PB1)

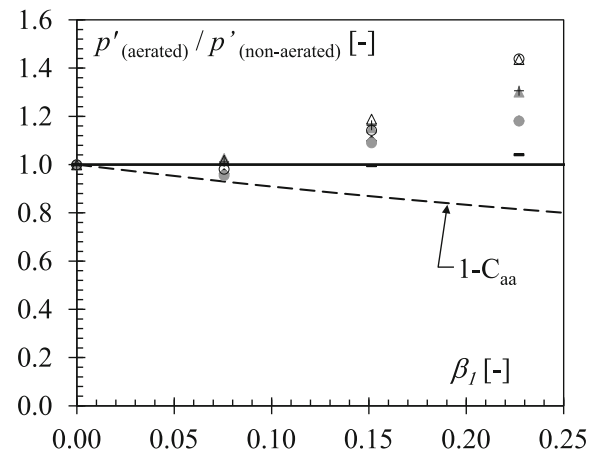

(b) Submerged jet, fissure entrance (VF1)

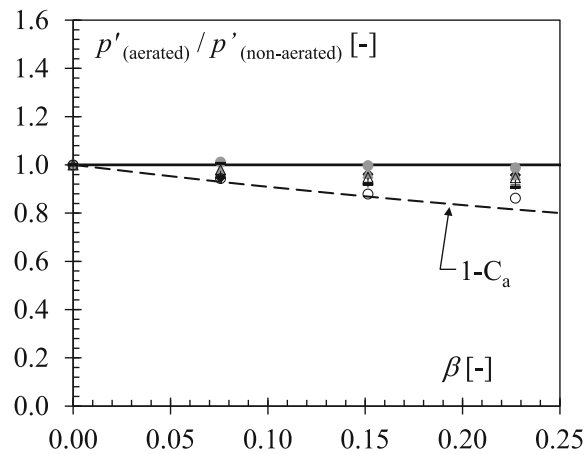

(d) Plunging jet, fissure entrance (VF1)

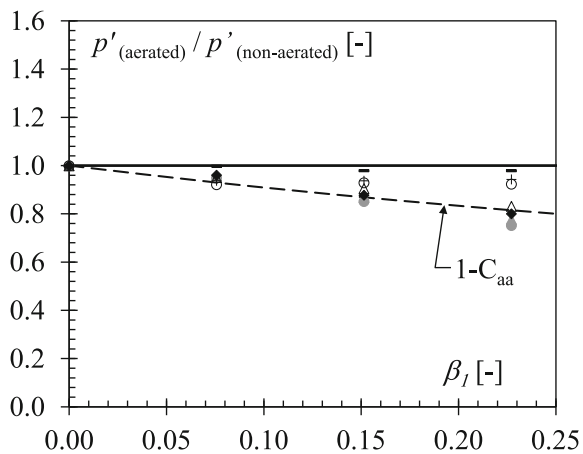

Fig. 11 Relative aerated RMS as a function of the incoming jet aeration, centered jets, fixed block; a, b submerged jets, $Y / d_{j}=9.7, \mathbf{c}, \mathbf{d}$ plunging jets, $Y / d_{j}=11.1$, a, $\mathbf{c}$ stagnation (PB1) and $\mathbf{b}, \mathbf{d}$ fissure entrance (VF1); (minus) $V_{a w}=7.4 \mathrm{~m} / \mathrm{s}$, (plus) $V_{a w}=9.8 \mathrm{~m} / \mathrm{s}$, (open circles) $V_{a w}=12.3 \mathrm{~m} / \mathrm{s}$, (open triangles) $V_{a w}=$ $14.7 \mathrm{~m} / \mathrm{s}$, (filled triangles) $V_{a w}=17.2 \mathrm{~m} / \mathrm{s}$, (filled circles) $V_{a w}=19.6 \mathrm{~m} / \mathrm{s}$, (filled diamonds) $V_{a w}=22.1 \mathrm{~m} / \mathrm{s}$, (dashed line) $1-C_{a a}$

(a)

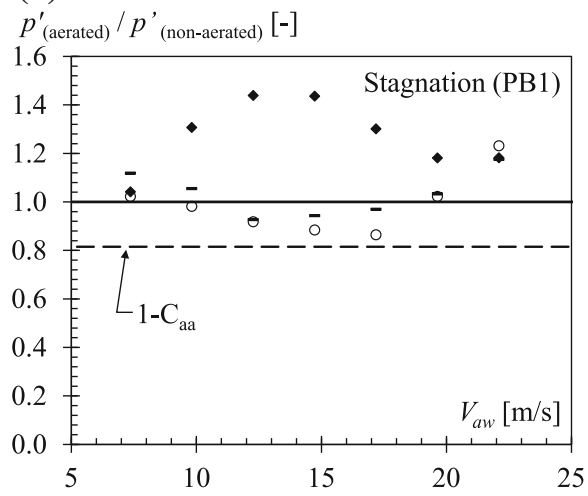

(b)

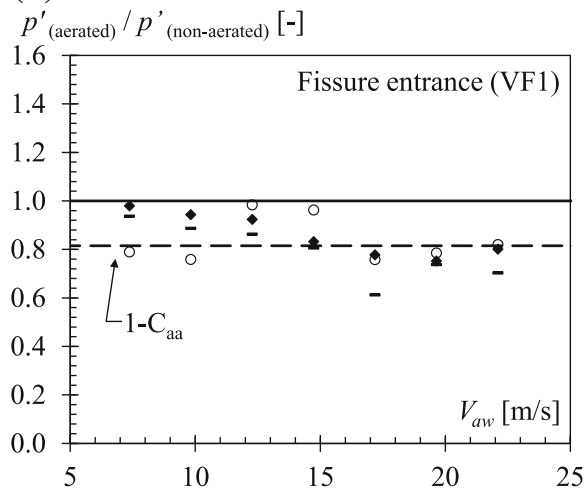

Fig. 12 Relative aerated RMS for aerated jets $\left(\beta_{1}=23 \%\right)$ divided by the relative aerated RMS of the similar non-aerated jet as a function of $V_{a w}$ for different relative pool depths, centered plunging jets, fixed block; a stagnation $(P B 1)$ and $\mathbf{b}$ fissure entrance $(V F 1)$, (minus) $Y / d_{j}=4.2$, (open circles) $Y / d_{j}=6.9$, (filled diamonds) $Y / d_{j}=11.1,($ dashed line $) 1-C_{a a}$ 


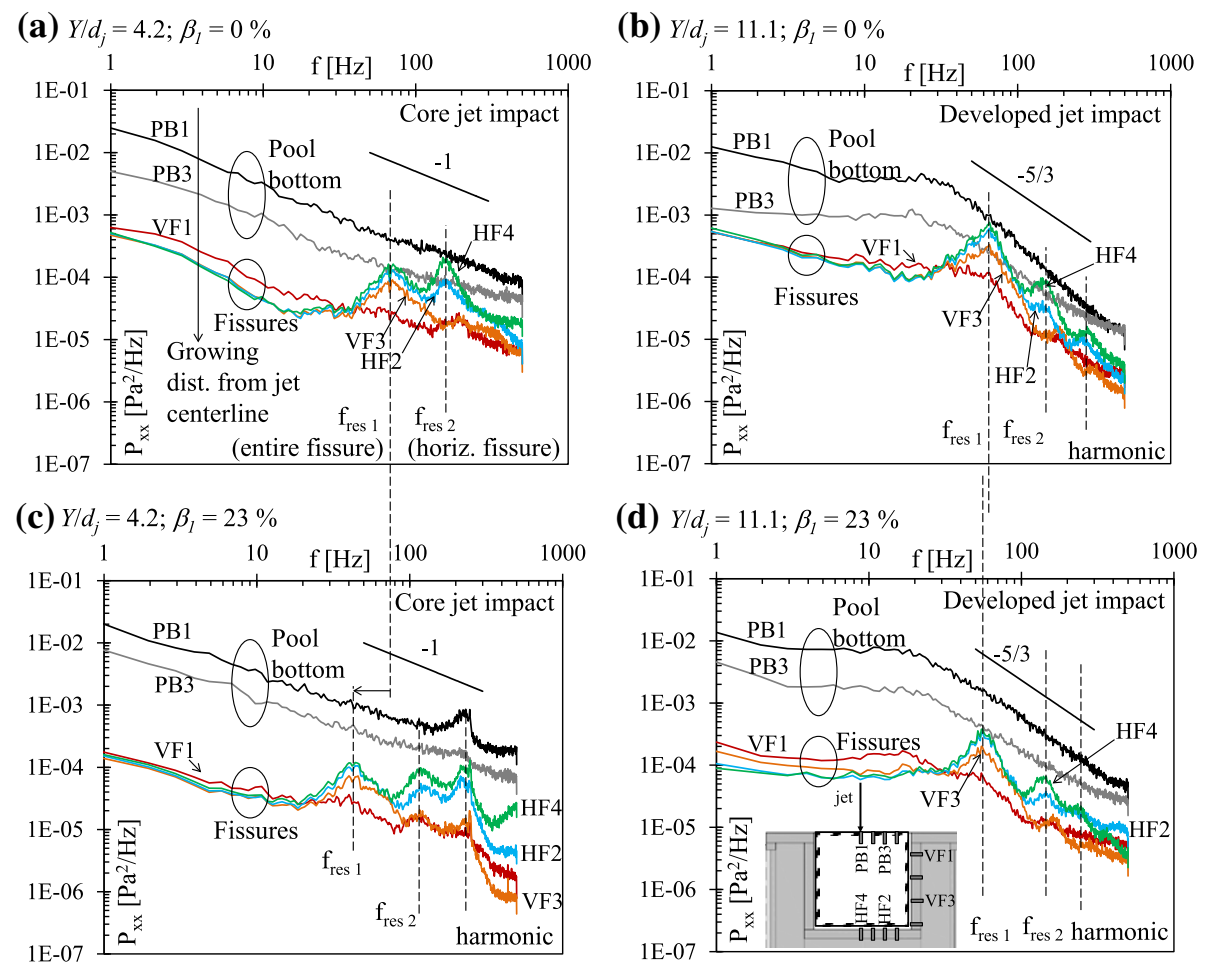

Fig. 13 PSD of the dynamic pressure signals at selected positions around the fixed block; centered plunging jets, $V_{a w}=22.1 \mathrm{~m} / \mathrm{s}$, above non-aerated jets a $Y / d_{j}=4.2, \beta_{1}=0 \%$, b $Y / d_{j}=11.1, \beta_{1}=0 \%$, below aerated jets $\mathbf{c} Y / d_{j}=4.2, \beta_{1}=23 \%$, and $\mathbf{d} Y / d_{j}=11.1, \beta_{1}=23 \%$

In the milestone work of Kolmogoroff [23] on the turbulence structure of incompressible fluid flows, it was stated that the turbulence energy is transferred as a power function of the eddies frequency. A core jet impacts the bottom when the relative pool depth is small. That means that the shear layer is not large and the turbulent eddies are of reduced size. Thus, the core jets result in spectral energy production at a large range of frequencies, including high frequencies, and a steady decay slope of -1 (Fig. 13a, c).

On the other hand, a developed jet impact on the bottom takes place when the pool is relatively deep. The shear layer of the diffusing jet is larger and the spectral energy is produced at lower frequencies, limited by the turbulence length scale which is limited by the largest eddy size. Then, the spectral content decays at a slope of $-5 / 3$ (Fig. 13b, d), in the inertial range of scales where no energy is produced, towards viscous energy dissipation in the form of heat in the smallest scales.

The turbulence length scale is determined by the frequency where the change in slope towards a $-5 / 3$ decay is observed. Although the exact frequency is difficult to determine, the analysis of Fig. 13b, d suggest that, for the non-aerated jet, $f=30 \mathrm{~Hz}$, while, for the aerated jet with $\beta_{1}=23 \%, f=20 \mathrm{~Hz}$. The turbulence length scale $L_{s}$ can then be calculated on the pool bottom with $L_{s}=V / f$.

Using the measured mean pressures as the kinetic energy per unit volume at stagnation and Eq. 2, the jets issued with a velocity of $V_{a w}=22.1 \mathrm{~m} / \mathrm{s}$ reach the bottom with $15.1 \mathrm{~m} / \mathrm{s}$ $\left(\beta_{1}=0 \%\right)$ and $17.4 \mathrm{~m} / \mathrm{s}\left(\beta_{1}=23 \%\right)$. This leads to length scales of approximately $0.50 \mathrm{~m}$ 


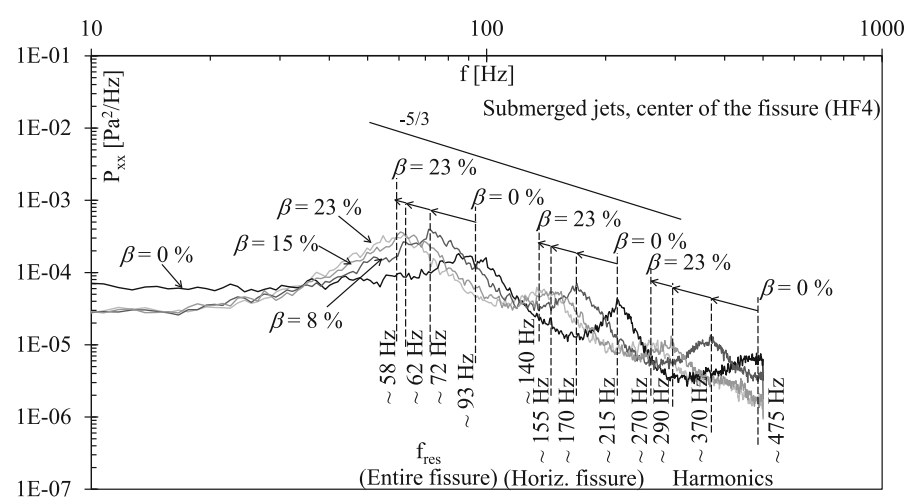

Fig. 14 PSD of the dynamic pressure signals at the center of the fissure (position HF4) for submerged jets; $V_{a w}=22.1 \mathrm{~m} / \mathrm{s}$, above non-aerated jets (black line $) \beta=0 \%,($ dark grey line $) \beta=8 \%,($ grey line $) \beta=15 \%$, (light grey line) $\beta=23 \%$

$\left(\beta_{1}=0 \%\right)$ and $0.87 \mathrm{~m}\left(\beta_{1}=23 \%\right)$. This is an approximation since it is difficult to determine the exact frequencies. Nevertheless it shows clearly that the aeration of the jet change the structure of the diffusing jet by enlarging its shear layer.

The transient effects inside the fissures are certainly the most evident feature in Fig. 13. If the spectral energy decreases with the distance from the jet centerline at low frequencies, an inversion occurs as a consequence of wave superposition at higher frequencies. The symmetric layout dictates that the highest resonance peaks are observed for the position HF4. The peaks observed at lower frequencies, denoted as $f_{\text {res } 1}$, correspond to resonance frequencies of pressure waves travelling the entire fissure around the block, while the second peaks, denoted as $f_{\text {res } 2}$, are a consequence of partial wave reflections in the horizontal fissure.

The aerated jets produced lower resonance peaks compared to the non-aerated jets. In the case of core jet impact, the aerated jet produced a relevant shift of the resonance frequency $f_{\text {res } 1}$ towards a lower value. The PSD estimates show $f_{\text {res } 1}=65 \mathrm{~Hz}$ approximately for the non-aerated jet and $f_{\text {res } 1}=40 \mathrm{~Hz}$ approximately for the jet with $\beta_{1}=23 \%$. Although difficult to visualize, a small shift also took place for the developed jet impact, where again $f_{\text {res } 1}=65 \mathrm{~Hz}$ approximately for the non-aerated jet and $f_{\text {res } 1}=55 \mathrm{~Hz}$ approximately for the jet with $\beta_{1}=23 \%$.

A lower resonance frequency is related to a reduction in wave celerity due to the presence of air bubbles. This provides experimental evidence that the air bubbles were capable of entering the fissures and of modifying resonance properties. The influence of the total jet aeration on the resonance phenomena is analyzed for the submerged jet case in Fig. 14. The spectral densities of the pressure fluctuations at the center of the fissure (HF4) are compared for jets with different air contents. The resonance frequencies are highlighted and are directly influenced by the jet aeration.

The pressure wave celerity inside the open-ended fissure can be calculated using $c=f_{\text {res }} \times 2 L_{f}$, where $L_{f}$ is the fissure length. The experimental results of the wave celerity as a function of jet aeration $\beta$ for the submerged jets with different velocities are shown in Fig. 15. The celerity is reduced following a power-law of the jet aeration. The celerity has an average at approximately $104 \mathrm{~m} / \mathrm{s}$ for the non-aerated jets and approaches the value of $70 \mathrm{~m} / \mathrm{s}$ for high jet aerations.

These values of pressure wave celerity are much lower than the celerity values for unbounded clear-water media $\left(1,465 \mathrm{~m} / \mathrm{s}\right.$ at $\left.15^{\circ} \mathrm{C}\right)$ and air media $\left(340 \mathrm{~m} / \mathrm{s}\right.$ at $\left.15^{\circ} \mathrm{C}\right)$ [5]. Pressure waves propagating inside fissures are influenced by the fluid-structure interactions 
Fig. 15 Celerity of the pressure waves for submerged jets as a function of the jet aeration $\beta$; fixed block, (open circles) $V_{a w}=12.3 \mathrm{~m} / \mathrm{s}$, (open triangles) $V_{a w}=14.7 \mathrm{~m} / \mathrm{s}$, (filled triangles) $V_{a w}=17.2 \mathrm{~m} / \mathrm{s}$, (filled grey circles) $V_{a w}=19.6 \mathrm{~m} / \mathrm{s}$, (filled black circles) $V_{a w}=22.1 \mathrm{~m} / \mathrm{s}$, (black line) general trend, (dashed line) asymptotic value at $70 \mathrm{~m} / \mathrm{s}$

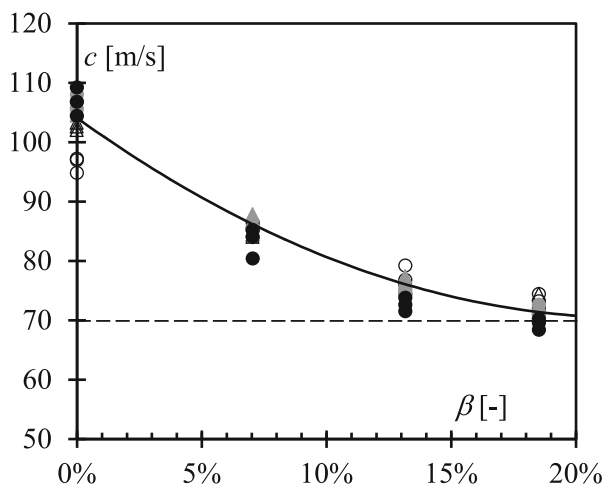

with the flow boundaries. Analogy is made with the water-hammer phenomenon in closedconduits, where pressure wave celerity is known to be dampened by the elastic behavior of the conduit [21]. In this study, although it was fixed inside the cavity, the block vibrates when impacted by the jet, which explains the low celerity results.

\section{Conclusions}

A systematic experimental study was carried out to assess the influence air entrained by high-velocity jets on the dynamic pressures applied on the bottom of a plunge pool and inside underlying fissures. Vertical water jets with different issuance velocities and aerations impinged into a water pool and the resulting dynamic pressures were measured on 12 different positions uniformly distributed along one half of a cubic block embedded on the bottom.

The different test configurations also compared plunging and submerged jets and jet impingement on the center or on the side of the block. The pressures around the block were investigated in term of the time-averaged pressures, pressure fluctuations, extreme pressure values and the spectral energy of the pressure fluctuations.

A relationship is suggested to describe the time-averaged pressures on the pool bottom at the jet centerline as a function of the relative pool depth by coupling pressure measurements at stagnation with velocity measurements in the jet centerline performed by the Authors.

It was found that the entrainment of air bubbles produce two opposed effects. First, an aerated jet, due to its lower apparent density, has less momentum than a similar clear-water jet. This effect contributes to lower pressures on the pool bottom. Second, the entrained air bubbles lower the shear stresses of the dissipating jet in the pool, allowing the aerated jets to flow with higher velocity. This effect contributes to a pressure rise, mainly close to the jet centerline. The influence of air entrainment is a balance of these two effects. However, inside the fissures, most often the aerated jets produced lower mean pressures and oscillations, tendency that is enhanced for high-velocity jets. For rock scour assessment, this indicates that jet air entrainment contributes to diminish rock erosion at the pool bottom.

Additionally, the spectral densities of the pressure fluctuations showed that the air bubbles were able to enter the fissures and to modify the resonance properties of the pressure waves. Aerated jets produced lower resonance peak values, and altered the resonance frequency due to the change in wave celerity.

Acknowledgments This research project is funded by the Fundação para a Ciência e a Tecnologia (FCT, Portugal, Grant No. SFPH/BD/51074/2010) and LCH-EPFL. 


\section{References}

1. Bellin A, Fiorotto V (1995) Direct dynamic force measurement on slabs in spillway stilling basins. J Hydraul Eng (ASCE) 121(10):686-693. doi:10.1061/(ASCE)0733-9429(1995)121:10(686)

2. Beltaos S, Rajaratnam N (1974) Impinging circular turbulent jets. J Hydraul Eng Div (ASCE) 100(NHY10):1313-1328

3. Beltaos S, Rajaratnam N (1977) Impingement of axisymmetric developing jets. J Hydraul Res 15(4):311326. doi:10.1080/00221687709499637

4. Bin AK (1993) Gas entrainment by plunging liquid jets. Chem Eng Sci 48(21):3585-3630. doi:10.1016/ 0009-2509(93)81019-r

5. Blevins RD (1984) Applied fluid dynamics handbook. Van Nostrand Reinhold Company, Inc., New York

6. Bollaert E (2002) Transient water pressures in joints and formation of rock scour due to high-velocity jet impact. In: Schleiss AJ (ed) Communication 13. Laboratory of Hydraulic Constructions (LCH), Ecole Polytechnique Fédérale de Lausanne (EPFL), Lausanne

7. Bollaert E, Schleiss A (2003a) Scour of rock due to the impact of plunging high velocity jets. Part I: a state-of-the-art review. J Hydraul Res 41(5):451-464. doi:10.1080/00221680309499991

8. Bollaert E, Schleiss A (2003b) Scour of rock due to the impact of plunging high velocity jets. Part II: experimental results of dynamic pressures at pool bottoms and in one- and two-dimensional closed end rock joints. J Hydraul Res 41(5):465-480. doi:10.1080/00221680309499992

9. Bollaert E, Schleiss A (2005) Physically based model for evaluation of rock scour due to high-velocity jet impact. J Hydraul Eng (ASCE) 131(no 3):153-165. doi:10.1061/(ASCE)0733-9429(2005)131:3(153)

10. Chanson H (1997) Air bubble entrainment in free-surface turbulent shear flows. Academic Press, London

11. Chanson $\mathrm{H}$ (2009) Turbulent air-water flows in hydraulic structures: dynamic similarity and scale effects. Environ Fluid Mech 9(2):125-142

12. Chanson H, Aoki S, Hoque A (2004) Physical modelling and similitude of air bubble entrainment at vertical circular plunging jets. Chem Eng Sci 59(4):747-758. doi:10.1016/j.ces.2003.11.016

13. Duarte R (2013) Air concentrations in plunge pools due to aerated plunging high-velocity jets and dynamic pressures in underlying fissures. In: Proceedings of 35th IAHR world congress, Chengdu, China, 8-13 September

14. Duarte R, Schleiss A, Pinheiro A (2013) Dynamic pressure distribution around a fixed confined block impacted by plunging and aerated water jets. In: Proceedings of 35th IAHR world congress, Chengdu, China, 8-13 September

15. Duarte R, Schleiss AJ, Pinheiro A (2014) Discussion on CFD analysis of the effect of nozzle stand-off distance on turbulent impinging jets. Can J Civ Eng 1-2. doi:10.1139/cjce-2013-0540

16. Ervine DA (1998) Air entrainment in hydraulic structures: a review. Proc Inst Civ Eng Water Manag 130(3):12. doi:10.1680/iwtme.1998.30973

17. Ervine DA, Falvey HT (1987) Behavior of turbulent jets in the atmosphere and in plunge pools. Proc Inst Civ Eng 2 83:295-314

18. Ervine DA, Falvey HT, Withers W (1997) Pressure fluctuations on plunge pool floors. J Hydraul Res 35(2):257-279

19. Federspiel MPEA (2011) Response of an embedded block impacted by high-velocity jets. In: Schleiss AJ (ed) Communication 47. Laboratory of Hydraulic Constructions (LCH), Ecole Polytechnique Fédérale de Lausanne (EPFL), Lausanne. doi:10.5075/epfl-thesis-5160

20. Fiorotto V, Rinaldo A (1992) Turbulent pressure fluctuations under hydraulic jumps. J Hydraul Res 30(4):499-520. doi:10.1080/00221689209498897

21. Hachem FE, Schleiss AJ (2011) A review of wave celerity in frictionless and axisymmetrical steel-lined pressure tunnels. J Fluid Struct 27(2):311-328. doi:10.1016/j.jfluidstructs.2010.11.009

22. Heller V (2011) Scale effects in physical hydraulic engineering models. J Hydraul Res 49(3):293-306. doi:10.1080/00221686.2011.578914

23. Kolmogoroff A (1941) The local structure of turbulence in incompressible viscous fluid for very large Reynolds numbers. C R Acad Sci URSS 30:301-305

24. Manso PFA (2006) The influence of pool geometry and induced flow patterns in rock scour by highvelocity plunging jets. In: Schleiss AJ (ed) Communication 25. Laboratory of Hydraulic Constructions (LCH), Ecole Polytechnique Fédérale de Lausanne (EPFL), Lausanne

25. Manso PFA, Bollaert EFR, Schleiss AJ (2008) Evaluation of high-velocity plunging jet-issuing characteristics as a basis for plunge pool analysis. J Hydraul Res 46(2):147-157. doi:10.1080/00221686.2008. 9521852

26. Melo JF, Pinheiro AN, Ramos CM (2006) Forces on plunge pool slabs: influence of joints location and width. J Hydraul Eng (ASCE) 132(1):49-60. doi:10.1061/(asce)0733-9429(2006)132:1(49) 
27. Müller G, Hull P, Allsop W, Bruce T, Cooker M, Franco L (2002) Wave effects on blockwork structures: model tests. J Hydraul Res 40(2):117-124. doi:10.1080/00221680209499854

28. Pinheiro AN, Melo JF (2008) Effect of jet aeration on hydrodynamic forces on plunge pool floors. Can J Civ Eng 35(5):521-530. doi:10.1139/107-138 